\title{
REDECA
}

CI ÊNCIAS CONTÁBEIS

ATUÁRIA E MÉTODOS QUANTITATIVOS

\section{O COMBATE À EVASÃO FISCAL DO IMPOSTO SOBRE A RENDA da PESSOA FÍSICA}

\author{
Marcus Vinicius Moreira Zittei ${ }^{1}$ \\ Cintia Aparecida dos Santos ${ }^{2}$ \\ Leonardo Fabris Lugoboni ${ }^{3}$
}

\begin{abstract}
Resumo
Este estudo tem por objetivo, a partir de uma abordagem descritiva, verificar o impacto das obrigações acessórias no combate a evasão fiscal do imposto sobre a renda da pessoa física no período de 2002 a 2012. Para tanto, é apresentado um referencial teórico que traz o processo pelo qual a Receita Federal passou, para chegar até a era digital e a suspensão da entrega das declarações de imposto sobre a renda em formato de papel, além de apresentar a lei que trata que a evasão fiscal é reconhecida como crime contra o Estado e opiniões de estudiosos, sobre a evasão fiscal. É uma pesquisa documental, onde foi utilizada a coleta de dados através de sites, como Receita Federal, Ministério da Fazenda, que ajudaram a concluir que a quando a Receita Federal entrou na era digital, evidenciado principalmente com a criação das obrigações acessórias, houve o aumento da entrega das declarações de imposto sobre a renda da pessoa física e consequentemente aumento a fiscalização quando a Receita Federal começou a analisar em conjunto as declarações de imposto sobre a renda da pessoa física e outras declarações como a DMED, para confrontar as informações apresentadas, assim demonstrando a diminuição da evasão fiscal.
\end{abstract}

Palavras-chave: Tributos, Obrigações Acessórias, Evasão Fiscal.

\footnotetext{
${ }^{1}$ Mestrado em Ciências Contábeis pelo Centro Universitário FECAP (2008) e doutorado em Ciências Contábeis e Administração pela Fundação Universidade Regional de Blumenau (2016)

2

${ }^{3}$ Fecap
}

Redeca, v.6, n.2. Jul-Dez. 2019 p. 128-149. 


\title{
REDECA
}

\section{CI ÊNCIAS CONTÁBEIS}

\begin{abstract}
This study aims, from a descriptive approach to verify the impact of acessory obligations in combating tax evasion tax income of the person physically in the period 2002-2012. To this end, we present a theoretical reference that brings the process by which the IRS has to get to the digital age and the suspension of the delivery of statements of the income tax in paper, besides presenting the law treats the tax evasion is recognized as a crime against the state and scholars opinions on tax evasion. It is a documentary research, which was used to collect data through websites such as IRS, Ministry of Farm, which helped to conclude that when the IRS entered the digital age, evidenced mainly by the creation of acessory obligations, there was increased delivery of statements of the income tax of the person physically and consequently increase the inspection when the IRS began to examine together the statements of the income tax of the person physically and other statements as DMED to confront the information presented, thus demonstrating the reduction of tax evasion.
\end{abstract}

Keywords: Taxes, Accessory Obligations, Tax Evasion. 
Zittei, M. V. M., Santos, C. A., Lugoboni, L. F.; O Combate à Evasão Fiscal do Imposto sobre a Renda da Pessoa Física.

\section{INTRODUÇÃO}

O alto índice da carga de tributária aliada ao alto custo para manter a subsistência da própria vida, aliado ao aumento dos gastos da máquina pública, fez com que o contribuinte procurasse de uma maneira indiscriminada, meios para a diminuição do pagamento desses tributos, surgindo assim, a evasão fiscal.

Pode-se notar que o aparecimento da evasão fiscal, está relacionado ao processo histórico de "desenvolvimento da produção, aumento das riquezas, uma valorização jurídica e moral maior das relações de propriedade, métodos de vigilância mais rigorosos, um policiamento mais estreito da população, técnicas mais bem ajustadas, de descoberta de captura, de informação" (FOUCAULT, 1989, P.72).

A evasão fiscal é um meio de o contribuinte evadir-se ao cumprimento das obrigações tributárias determinadas pelo Fisco, Marins (2002, P.30) defini a elisão fiscal da seguinte forma:

A evasão tributária é a economia ilícita ou fraudulenta de tributos porque sua realização passa necessariamente pelo incumprimento de regras de conduta tributária ou pela utilização de fraudes. A transgressão às regras tributárias caracteriza a evasão.

É possível verificar, que a evasão fiscal é considerada um ato ilícito, contra qual o Fisco deve aramar-se da melhor maneira possível, a partir da constatação da má-fé do contribuinte, vale ressaltar que a evasão fiscal está prevista e capitulada na Lei dos Crimes Contra a Ordem Tributária, Econômica e Contra as Relações de Consumo (Lei n ${ }^{\circ}$ 8.137/90) em seus artigos. $1^{\circ}$ e $2^{\circ}$ (BRASIL, 1990).

A evasão fiscal é percebida, quando o contribuinte deixa de cumprir com alguma obrigação tributária principal e acessória. De acordo com Machado (2002, P.110-112), obrigação tributária principal e acessória pode ser definida da seguinte forma:

[...] em Direito Tributário as obrigações acessórias não precisariam existir se não existissem as obrigações principais. São acessórias neste sentido. Só existem em função das principais, embora não exista necessariamente um liame entre determinada obrigação principal e determinada obrigação acessória. Todo o conjunto de obrigações acessórias existe para viabilizar o cumprimento de obrigações principais. 
Zittei, M. V. M., Santos, C. A., Lugoboni, L. F.; O Combate à Evasão Fiscal do Imposto sobre a Renda da Pessoa Física.

No entanto, a divisão em obrigação principal e acessória leva em conta mais as suas finalidades, do que a dependência da acessória em relação à principal. A finalidade da obrigação tributária principal é o pagamento do tributo, enquanto da acessória é o de assegurar ou facilitar o cumprimento da primeira.

Um dos tributos que o contribuinte de alguma forma tenta evadir-se é o IRPF (Imposto de Renda Pessoa Física), o qual está ligado diretamente aos rendimentos recebidos pelo contribuinte em um determinado período, que deverá ser declarado através da obrigação acessória DIRPF (Declaração do Imposto sobre a Renda da Pessoa Física). De acordo com Queiroz (2003, P.239), a incidência do imposto sobre a renda se define da seguinte forma:

Renda e proventos de qualquer natureza (ou renda em sentido amplo ou simplesmente renda) é o conceito que está contido em normas constitucionais relativas ao imposto sobre a renda e proventos de qualquer natureza e que designa o acréscimo de valor patrimonial, representativo da obtenção de produto ou de simples aumento no valor do patrimônio, apurado em certo período de tempo, a partir da combinação de todos os fatos que contribuem para o acréscimo do valor do patrimônio (fatos-acréscimos) com certos fatos que, estando relacionados ao atendimento das necessidades vitais básicas ou à preservação da existência, com dignidade, tendo da própria pessoa quanto de sua família, contribuem para o decréscimo de valor do patrimônio (fatos-decréscimos).

O imposto de renda, como tributo geral e universal, deve, em princípio, atingir a todas as pessoas e todas as formas de rendimento, em razão do princípio da capacidade contributiva e da igualdade.

As considerações apresentadas demonstraram que a Evasão Fiscal tem relação direta com o crescimento socioeconômico, o estudo tomará como base as atitudes do contribuinte e do Fisco, em relação à arrecadação dos tributos; onde o primeiro tenta de alguma maneira não cumprir com as obrigações tributárias e o segundo na exigência em arrecadar tais tributos.

Diante do contexto foi formulada a seguinte questão de pesquisa: Com as obrigações acessórias introduzidas no período de 2002 a 2012, qual a influência no Combate a Evasão Fiscal do Imposto Sobre a Renda da Pessoa Física?

Para responder a seguinte questão de pesquisa, este trabalho tem como objetivo geral identificar o impacto das Obrigações Acessórias no combate a Evasão Fiscal do Imposto Sobre a Renda da Pessoa Física, no período de 2002 a 2012, e como objetivos específicos: 
Zittei, M. V. M., Santos, C. A., Lugoboni, L. F.; O Combate à Evasão Fiscal do Imposto sobre a Renda da Pessoa Física.

a) Descrever as formas de Evasão Fiscal praticada pelos contribuintes;

b) Identificar as principais medidas tomadas pelo Governo para combater a Evasão Fiscal;

c) Demonstrar a eficácia e eficiência das medidas tomadas pelo Governo no combate a Evasão Fiscal.

Alguns dados apresentados pela Receita Federal em 2012, como a histórica arrecadação de tributos que ultrapassou a barreira do $\mathrm{R}$ \$ 1 trilhão anual. No total, as receitas da União somaram $\mathrm{R}$ \$ 1,029 trilhão, com o Imposto de Renda sendo responsável por R \$ 25 bilhões deste bolo (UOL ECONOMIA, 2012).

Mesmo com a alta arrecadação, a receita federal também divulgou que em 2012, 616.569 mil declarações ficaram retidas na malha fina, uma alta de $8,2 \%$ em relação a 2011. A omissão de rendimentos responde por $69,12 \%$ das declarações restritas. Os outros destaques são: despesas médicas $(11,6 \%)$, ausência de DIRF $(8,3 \%)$ e divergência de DIRF $(3,1 \%)$ (UOL ECONOMIA, 2012).

Conforme dados apresentados, o presente trabalho justifica-se pela importância de saber, se as medidas de combate à Evasão Fiscal, elaboradas pelo Governo no período de 2002 a 2012, teve efeito positivo na diminuição a evasão fiscal.

\section{REFERENCIAL TEORICO}

No presente item, serão tratados definições e conceitos sobre tributos, obrigações acessórias e evasão fiscal, além de apresentar as maneiras utilizadas pela Receita Federal para diminuir a Evasão Fiscal do imposto sobre a renda da pessoa física.

\subsection{Conceito de Tributos}

Ao tributo, pode-se dar a conotação de receita arrecadada pelo Estado, a sua atuação está voltada para obter, gerir e aplicar os recursos financeiros necessários à consecução de suas finalidades, que em última análise, se resumem na realização do bem comum (HARADA, 1995). 
Zittei, M. V. M., Santos, C. A., Lugoboni, L. F.; O Combate à Evasão Fiscal do Imposto sobre a Renda da Pessoa Física.

De acordo com Guimarães (1983), o tributo permaneceu sob vários aspectos doutrinários emergidos de legislação épica, na Grécia cobrou-se tributos como meio de defesa do bem coletivo os impostos sobre consumo, prestações livremente oferecidas. Em Roma considerado o berço doutrinário do Direito, os tributos eram propósitos para a proveniência dos recursos com fins de manter instituições, guerras, luxurias etc. além de atender às despesas das civilizações.

Levando em consideração o aspecto da obrigação, Hugon (1945, p.32) definiu tributo como sendo "uma contribuição obrigatória e de interesse geral, destinada a cobrir despesas do Estado”. No início do século XX o tributo passou da condição meramente fiscal, tornando-se uma ferramenta destinada a agir sobre o equilíbrio econômico. Conforme o autor Hugon (1945, P.27):

(...) é na teoria das despesas públicas que se coloca o estudo da política que se pode seguir, servindo-se do imposto em particular e da fiscalização em geral para agir sobre o desenvolvimento da atividade econômica.

A Lei ${ }^{\circ} 4.320$, de 17 de março de 1964, regulamentou o conceito de despesas e receitas, e em seu Art. $1^{\circ}$ - estatui normas gerais do direito financeiro para a elaboração e controle dos orçamentos e balanços da União, dos Estados, dos Municípios e do Distrito Federal (BRASIL, 1964). O Art. $3^{\circ}$ da Lei 5.172, de 25 de outubro de 1.966, conceitua tributo da seguinte forma:

Tributo é toda prestação pecuniária compulsória, em moeda ou cujo valor nela se possa exprimir, que não constitua sanção de ato ilícito, instituída em lei e cobrada mediante atividade administrativa plenamente vinculada (BRASIL, 1966).

De outra maneira: Tributo é uma prestação obrigatória, em dinheiro ou em outra unidade que pode ser traduzida em moeda (como UFIR), originada de ato lícito (uma vez que os acontecimentos ilícitos vêm sempre atrelados a uma providência sancionatória), que não pode ser instituído sem que lei o estabeleça e que constitui atividade privativa da administração pública, que deve agir estritamente conforme a legislação tributária (CARAVALHO,1988).

Os tributos estão divididos em impostos, taxas e contribuição de melhoria, conforme os artigos 145, 148 e 149 da Constituição Federal de 1988 e as Emendas Constitucionais nº 33/01 e $\mathrm{n}^{\circ}$ 42/03 (BRASIL, 1988, 2001, 2003).

Os tributos também podem ser classificados em Diretos ou Indiretos, o primeiro recai sobre a pessoa física ou jurídica que tem relação pessoal e direta com o fato gerador, incidindo 
Zittei, M. V. M., Santos, C. A., Lugoboni, L. F.; O Combate à Evasão Fiscal do Imposto sobre a Renda da Pessoa Física.

sobre o patrimônio e a renda (Ex. IRRF, IRPJ, IPTU, ITR, IPVA, etc.). O segundo incide sobre a produção e a circulação de bens e serviços e são repassados para preço, pelo produtor, vendedor ou prestador de serviços (Ex. ICMS, IPI, ISS, COFINS, etc.) (FABRETTI; FABRETTI, 2007).

\subsection{Tributos Federais}

No Brasil, todos os tributos estão submetidos ao regime das competências privativas, definidas pela Constituição Federal de 1988, em seus artigos 153 e 154, delimita sobre quais impostos a União tem permissão para instituir tais impostos (BRASIL, 1988).

Portanto, são considerados tributos federais aqueles de competência da União, independente da distribuição de sua arrecadação aos Estados, Distrito Federal ou Municípios.

\subsection{Tributos Pessoa Física.}

Quando se fala de tributos da pessoa física, o que se destaca é o Imposto Sobre a Renda que se enquadra na tributação direta, porém o contribuinte, também sofre tributação indireta, quando é um simples consumidor, pois o imposto indireto é aquele, cujo ônus financeiro do tributo é transferido ao consumidor final, por meio do fenômeno da repercussão econômica, não ligando o ônus tributário a um evento jurídico ou material e não dispondo de um parâmetro direto para apurar a capacidade econômica do contribuinte (SABBAG, 2011).

$\mathrm{O}$ autor também faz outra categorização, entre imposto real e imposto impessoal. $\mathrm{O}$ primeiro incide sobre um fato determinado, o que tributa todas as pessoas da mesma maneira, enquanto o imposto impessoal, leva em consideração as condições especiais do contribuinte, ou seja, a carga tributária final é diferenciada para cada contribuinte, conforme art. $145, \S 1^{\circ} \mathrm{da}$ CF/88 (SABBAG, 2011).

Quando se fala sobre o Imposto Sobre a Renda, não se pode deixar de falar da capacidade contributiva, Carvalho (2009, p.667 e 668), faz a seguinte consideração:

(...) diga-se de passagem, poucos são os tributos que se prestam à aferição da autêntica capacidade contributiva relativa como o imposto sobre a renda, dado sua forte índole de pessoalidade, sendo inteiramente possível ao legislador, por controlar a multiplicidade e a legitimidade dos ingressos e selecionando as quantias admitidas como dedutíveis, apurar o 
Zittei, M. V. M., Santos, C. A., Lugoboni, L. F.; O Combate à Evasão Fiscal do Imposto sobre a Renda da Pessoa Física.

verdadeiro saldo identificador da renda tributável ou da renda líquida, segundo o regime jurídico de incidência.

Ainda falando da Capacidade Contributiva, o Art.150, IV da CF/88 assegura que:

(...) Sem prejuízo de outras garantias asseguradas ao contribuinte, é vedado à União, aos Estados, ao Distrito Federal e aos Municípios:

$[\ldots]$

IV - utilizar tributo com efeito de confisco; (BRASIL, 1988).

Além da Capacidade Contributiva, também é importante considerar o critério de materialidade, de avaliação, utilizado pelo Governo para que o contribuinte possa oferecer a sua renda a tributação. A Lei $n^{\circ} 9.250$, de 26 de dezembro de 1995 , em seu artigo $3^{\circ}$ traz que o imposto de renda será calculado sobre os rendimentos de que tratam os artigos 7,8 e 12 da Lei $\mathrm{n}^{\circ} 7.713$, de 22 de dezembro de 1988, de acordo com a tabela progressiva em Reais e que será com base nos rendimentos efetivamente recebidos em cada mês (BRASIL, 1995,1988).

Outro fator importante é o temporal, quando há incidência desse imposto, de acordo com Carrazza (2009, P.128).

Neste imposto o aspecto temporal da hipótese de incidência ganha uma importância transcendental. De fato, é um tributo que só nasce após haver transcorrido um determinado lapso de tempo. Se, neste período, for constatada a existência de um saldo positivo, surgirá à obrigação tributária - e, com ela, o dever de recolher uma dada quantia de dinheiro aos cofres públicos. Já, se neste mesmo período, o saldo for negativo, não haverá tributo a pagar e, se for o caso, o contribuinte ainda terá direito à devolução do que tiver recolhido a maior, no sistema fonte.

Em complemento ao exposto, o artigo $7^{\circ}$ da Lei $\mathrm{n}^{\circ}$ 9.250, de 26 de dezembro de 1996, faz referência ao ano-calendário como estipulação de período legalmente considerado para apuração do imposto de renda devido, e que deverá ser apresentado anualmente até o último dia útil do mês de abril do ano-calendário subsequente (BRASIL, 1996).

A base de cálculo não pode ser esquecida, o CTN em seu Art. 44 "A base de cálculo do imposto é o montante, real, arbitrado ou presumido, da renda ou dos proventos tributáveis" (BRASIL, 1966). 
Zittei, M. V. M., Santos, C. A., Lugoboni, L. F.; O Combate à Evasão Fiscal do Imposto sobre a Renda da Pessoa Física.

Sabbag (2011, P.1081) demonstra de uma maneira simples de como é formada a base de cálculo do Imposto de Renda e essa definição está assegurada pela Lei 9.250/95 em seu $\operatorname{artigo} 8^{\circ}$.

A base de cálculo do imposto é a soma de fatores algébricos positivos e negativos que se agregam ao patrimônio, conforme se depreendem do art. 44 do CTN. É o montante real, arbitrado ou presumido, da renda ou do provento de qualquer natureza. Aliás, é bom que se memorize que não existe "renda presumida". Presumido ou arbitrado pode ser o montante da renda. Adota-se, no Brasil, um critério de aferição de base de cálculo "pelo montante absoluto da renda ou provento" (critério global ou unitário), segundo o qual as alíquotas incidem sobre o total dos rendimentos, independentemente de sua origem ou razão. Assim, a incidência ocorre sobre o crédito líquido do contribuinte, ou seja, a diferença entre a renda ou provento bruto auferido e os encargos admitidos em lei, tais como gastos com dependentes, planos de saúde etc. Devem-se somar todos os rendimentos e lucros de capital da pessoa física e seus dependentes (rendimento bruto) e subtrair os encargos (reais ou presumidos) autorizados pela legislação (rendimento líquido). Com a base de cálculo composta, há a necessidade de se encontrar alíquota correspondente, dessa forma utiliza-se a tabela progressiva do período em questão, as alíquotas são progressivas, sendo utilizadas conforme o valor da base de cálculo, ou seja, são utilizadas as maiores alíquotas quanto maior for à base de cálculo.

\subsection{Obrigações Acessórias}

A Obrigação acessória decorre da legislação tributária e têm por objeto as prestações, positivas ou negativas, nela previstas no interesse da arrecadação ou da fiscalização de tributos, premissa sustentada pelo Código Tributário Nacional em seus artigos 113 e 139; importante ressaltar, que a não apresentação da obrigação acessória a torna principal levando a penalidade pecuniária (BRASIL, 1966).

De uma maneira mais clara, entende-se por obrigação tributária acessória, como sendo aquela que exige do contribuinte um fazer, um não fazer ou até um tolerar. Decorrem da legislação tributária, e têm como principal objetivo viabilizar ao fisco o controle de fatos considerados como relevantes para o surgimento da obrigação principal (PAULSEN, 2005).

Uma das obrigações acessórias que a grande maioria dos brasileiros estão obrigados a apresentar é a Declaração de Ajuste Anual de Rendimentos, essa afirmação é assegurada pelo Regulamento de Imposto de Renda de 1999 em seu art. 787 (RECEITA FEDERAL, 2013a). 
Zittei, M. V. M., Santos, C. A., Lugoboni, L. F.; O Combate à Evasão Fiscal do Imposto sobre a Renda da Pessoa Física.

A Declaração de Ajuste Anual de Imposto de Renda sofreu muitas alterações, principalmente referente à sua apresentação junto a Secretaria da Receita Federal, porque a declaração do exercício de 1989, ano base 1988, foi a ultima com os rendimentos tributáveis e as deduções classificadas em cédulas de A até H, divisão que vinha desde o exercício de 1926 (RECEITA FEDERAL, 2013a).

Foi no inicio da década de 1990, quando os microcomputadores começaram a fazer parte do cotidiano de alguns contribuintes. Em 1991, a Receita Federal instituiu o programa de preenchimento da Declaração de Rendimentos do Imposto de Renda. Após 67 anos de criação do primeiro formulário, estava instituída a segunda forma de preencher e entregar a declaração: o meio magnético. A adesão não foi maciça, sobretudo porque a popularização dos microcomputadores estava começando, apenas 3\% dos declarantes entregaram a declaração em disquete (RECEITA FEDERAL, 2013b).

Além de a declaração ser por meio magnético, também foi instituído dois tipo de formulários: modelos, completo e opcional, nesse segundo modelo, o imposto era conhecido após o processamento eletrônico. Em 1996, voltou à opção pela declaração simplificada (que vigorou de 1976 a 1990), desde que o contribuinte tivesse recebido até o montante de $\mathrm{R} \$ 21.458,00$, o qual sofreria um desconto de $20 \%$ sobre os rendimentos tributáveis (RECEITA FEDERAL, 2013b).

Em 1997, devido ao grande crescimento tecnológico, para facilitar ainda mais o cumprimento das obrigações acessórias, foi criado um programa específico para transmissão de declarações, o Receitanet. O contribuinte já tinha condições de preencher a sua declaração e enviá-la via internet (RECEITA FEDERAL, 2013c).

Em 2007, nos termos da Lei nº 11.457 de 16 de março, a Secretaria da Receita Federal do Brasil passou a denominar-se Secretaria da Receita Federal do Brasil, órgão da administração diretamente subordinado ao Ministério do Estado da Fazenda, sendo responsável pela administração dos tributos de competência da União. A Declaração de Ajuste Anual de 2008 ano-calendário 2007, entregue via computador através do programa IRPF, teve adesão dos declarantes de 99\%, afirmando que a era digital veio pra ficar (RECEITA FEDERAL, 2013 d).

Em 2011 a Declaração de Ajuste Anual ano-calendário 2010, passou a ser obrigatória para todos em formato digital, sendo assim extinta de uma vez por todas as declarações entregues em papel (RECEITA FEDERAL, 2013e). 
Zittei, M. V. M., Santos, C. A., Lugoboni, L. F.; O Combate à Evasão Fiscal do Imposto sobre a Renda da Pessoa Física.

\subsection{Evasão Fiscal}

A Evasão Fiscal caracteriza-se pela forma ilícita do contribuinte cumprir ou não cumprir as obrigações tributárias que lhe são cabíveis. Nas palavras de Huck (1997, p.30), "há uma ação, ou uma série de atos marcados pelos elementos de engano, má interpretação, simulação, artificialidade, ocultamente e desonestidade.”.

Pereira (2001, P.66), diz que "sempre que o sujeito passivo utilize formas jurídicas anormais, inadequadas ou atípicas para alcançar efeito econômico, obtendo vantagem tributária, sem que tais formas jurídicas sejam justificáveis senão pelo interesse em obter a vantagem tributária”.

Em complemento, vale ressaltar que a evasão fiscal está prevista e capitulada na Lei dos Crimes contra a Ordem Tributária, Econômica e Contra as Relações de Consumo (Lei ${ }^{\circ}$ 8.137/90) em seus artigos $1^{\circ}$ e $2^{\circ}$ (BRASIL, 1990).

Peixoto (2004), baseado nos ensinamentos de Antônio Roberto Sampaio Dória, diversos doutrinadores abordaram exaustivamente as modalidades possíveis de evasão fiscal, este autor procurou conceituar os diversos tipos de evasão fiscal, proporcionando, um melhor entendimento. Dividiu a evasão fiscal em Omissiva aquela que pode ser praticada com a intenção (dolo) ou não (culpa) e comissiva, a qual conscientemente, o indivíduo, por meios ilícitos tende a eliminar, reduzir ou retardar o pagamento do tributo devido, havendo sempre a presença da intencionalidade.

\section{METODOLOGIA}

Nesse item, será apresentado, a metodologia utilizada no presente trabalho. Conforme Vergara (1997), método é um caminho, uma forma, uma lógica de pensamento.

Quanto à natureza, trata-se de uma pesquisa aplicada, ou pesquisa prática, voltada para intervir na realidade social (ANDRADE,2001).

Quanto aos objetivos, trata-se de uma pesquisa descritiva, Gil (1996), tem como objetivo primordial à descrição das características de determinada população ou fenômeno ou, então, o estabelecimento de relações entre variáveis. Essas pesquisas têm como preocupação central identificar os fatores que determinam ou que contribuem para a ocorrência dos fenômenos. Este 
Zittei, M. V. M., Santos, C. A., Lugoboni, L. F.; O Combate à Evasão Fiscal do Imposto sobre a Renda da Pessoa Física.

é o tipo de pesquisa que mais aprofunda o conhecimento da realidade, porque explica a razão, o porquê das coisas.

A técnica utilizada para a coleta de dados foi de pesquisa bibliográfica e a analise documental, uma vez que o trabalho foi elaborado a partir de material já publicado, constituído, principalmente de livros, artigos, e material disponibilizado na internet, e demais publicações que trouxeram contribuições para a fundamentação teórica sobre a Evasão Fiscal, Tributos e Obrigações Acessórias, possibilitando uma melhor compreensão do trabalho desenvolvido.

Como já citado, sites também foram utilizados para a coleta de dados, a pesquisa foi realizada nos sites da Receita Federal, onde foram extraídos dados como: Total das Receitas Anuais, a arrecadação do Imposto de Renda Pessoa Física no período de 2002 a 2012, período em que a Declaração de Imposto de Renda passou a ser eletrônica completa e digital a todos os contribuintes.

Outros sites também foram utilizados como: Ministério da Fazenda para coletar das do Crescimento Econômico, Bonna Consultores para pesquisar sobre a DIMOB, Jantsch e Kanomata Advogados para pesquisar sobre DMED, além de outros sites para pesquisar a quantidade de declarações entregues no período de 2002 a 2012 nos formatos em papel e digital, como: Dourado News, Folha de São Paulo, G1 Economia, Unafisco e Convergência Digital.

A coleta de dados possibilitou fazer a Correlação de Pearson entre a arrecadação do imposto de renda pessoa física e o surgimento das obrigações acessórias, através da padronização (utilizando à média e o desvio padrão) dos números. 
Zittei, M. V. M., Santos, C. A., Lugoboni, L. F.; O Combate à Evasão Fiscal do Imposto sobre a Renda da Pessoa Física.

\section{DISCUSSÃO DOS RESULTADOS}

Conforme mencionado na metodologia, foi utilizada a Correlação de Pearson para analisar alguns dados, entre a arrecadação do imposto de renda pessoa física e outros fatores, como: crescimento econômico, declaração de imposto de renda pessoa física entregue em formato de papel e em digital e o surgimento de outras declarações, que influenciaram, na apresentação da declaração do imposto de renda pessoa física.

A seguir a tabela 1 apresenta a correlação entre a arrecadação do imposto de renda pessoa física (IRPF_P) e o crescimento econômico (CRESCECON_P).

\begin{tabular}{ll|c|c}
\hline & IRPF_P & CRESCECON_P \\
\hline & Correlação de Pearson & 1 &,- 068 \\
IRPF_P & Sig. (2 extremidades) & &, 843 \\
& $\mathrm{~N}$ & 11 & 11 \\
\hline
\end{tabular}

Tabela 1 - Correlação: IRPF X Crescimento Econômico

Fonte: Dados da Pesquisa

De acordo com os dados apresentados, pode-se verificar que o CRESCECON_P não teve influência significativa na arrecadação do IRPF_P, no período de 2002 a 2012.

A tabela 2 traz a correlação entre a arrecadação do imposto de renda e as declarações entregues em formato de papel e digital.

\begin{tabular}{|c|c|c|c|c|}
\hline & & $\mathrm{IRPF}_{-}$ & PAPEL_ & DIGITAL_ \\
\hline \multirow{4}{*}{ IRPF_P } & Correlaçã & 1 &,$- 872 * *$ & ,874** \\
\hline & o de Pearson & & & \\
\hline & $\begin{array}{c}\text { Sig. } \\
\text { extremidades) }\end{array}$ & & ,000 & ,000 \\
\hline & $\mathrm{N}$ & 11 & 11 & 11 \\
\hline & Correlaçã &,$- 872 * *$ & 1 &,$- 868 * *$ \\
\hline PAPEL_P & $\begin{array}{l}\text { o de Pearson } \\
\text { Sig. } \\
\text { extremidades) }\end{array}$ & ,000 & & ,001 \\
\hline
\end{tabular}


Zittei, M. V. M., Santos, C. A., Lugoboni, L. F.; O Combate à Evasão Fiscal do Imposto sobre a Renda da Pessoa Física.

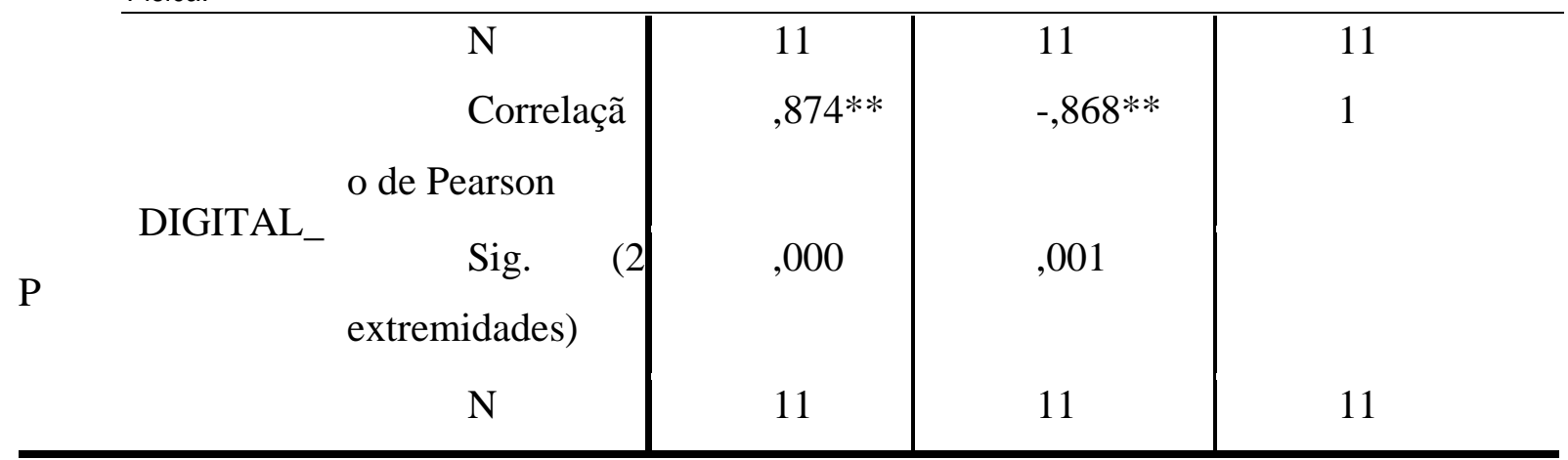

Tabela 2 - Correlação: IRPF X Declarações em Papel e Digital

Fonte: Dados da Pesquisa

**. A correlação é significativa no nível 0,01 (2 extremidades).

A correlação entre a declaração de imposto de renda pessoa física entregues em formato de papel e digital, demonstra que quando os contribuintes começaram a aderir à nova tecnologia, que em 2007 teve a maior expressão, a adesão dos contribuintes foi de quase 99\% de acordo com os dados da Receita Federal, consequentemente diminuía a entrega das declarações de imposto de renda pessoa física em formato de papel e aumentavam as entregas de declarações de imposto de renda pessoa física via internet.

Existe uma correlação positiva entre a arrecadação do Imposto de Renda Pessoa Física e a Declaração Digital $(0,874)$, assim percebe-se, que quando aumenta a declaração digital, aumenta declaração imposto de renda.

Confirmando essa relação, perceber-se que existe uma correlação negativa $(-0,872)$, entre a declaração em papel e a arrecadação do Imposto de Renda, ou seja, diminui o número de declarações entregues em papel e aumenta a declaração do Imposto de Renda.

A tabela 3 traz a correlação entre a declaração de imposto de renda pessoa física e outras declarações digitais, como a DIMOB e DMED.

\begin{tabular}{|c|c|c|c|c|c|c|}
\hline & & $\begin{array}{ll} & \text { IRPF } \\
& \end{array}$ & $\begin{array}{ll}\text { ANTERI } \\
\text { OR }\end{array}$ & $\begin{array}{ll} & \text { DIM } \\
\text { OB } & \end{array}$ & ED & $\mathbf{D M}$ \\
\hline & $\begin{array}{r}\text { Correla } \\
\text { ção de Pearson }\end{array}$ & 1 & a & ,395 & ** &, 812 \\
\hline IRPF_P & $\begin{array}{c}\text { Sig. }(2 \\
\text { extremidades) }\end{array}$ & & . & ,229 & &, 002 \\
\hline & $\mathrm{N}$ & 11 & 11 & 11 & & 11 \\
\hline
\end{tabular}


Zittei, M. V. M., Santos, C. A., Lugoboni, L. F.; O Combate à Evasão Fiscal do Imposto sobre a Renda da Pessoa Física.

$\mathrm{R}$

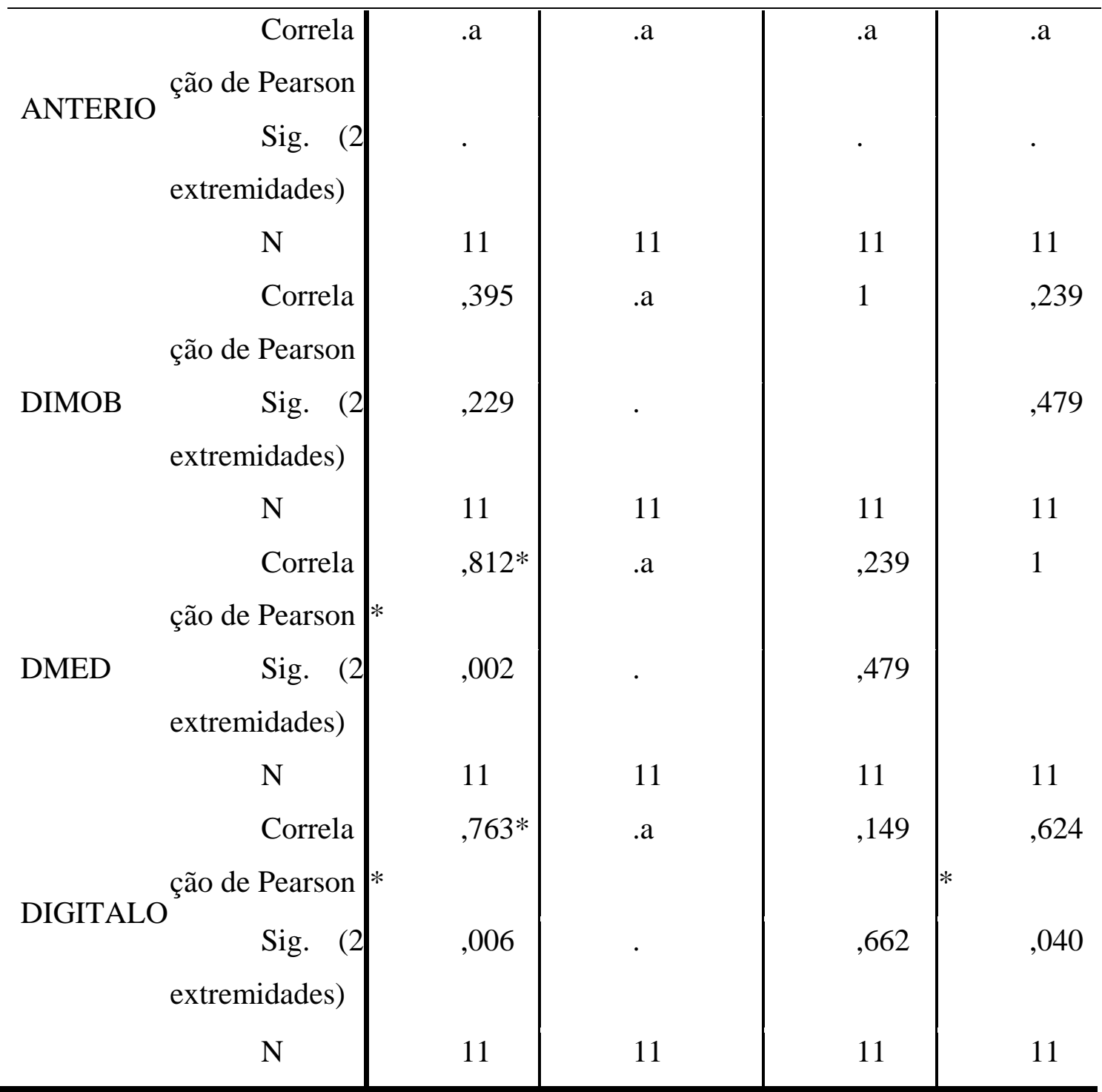

Tabela 3 - Correlação: IRPF x DIMOB x DMED x Declaração Digital

Fonte: Dados da Pesquisa

**. A correlação é significativa no nível 0,01 (2 extremidades).

*. A correlação é significativa no nível 0,05 (2 extremidades).

a. Não é possível calcular porque pelo menos uma das variáveis é constante.

Os dados acima demonstram que a entrega da declaração de imposto de renda pessoa física em formato digital, confirma o aumento da arrecadação apresentando uma correlação positiva de (0,763). Entretanto a correlação entre a declaração de imposto de renda pessoa física e a DIMOB, não teve influência no período de 2002 a 2012, porque a mesma foi criada no período de 1993, não sendo possível apresentar uma correlação precisa. 
Zittei, M. V. M., Santos, C. A., Lugoboni, L. F.; O Combate à Evasão Fiscal do Imposto sobre a Renda da Pessoa Física.

Porém a DMED que foi criada em 2009 teve grande influência no aumento da arrecadação do imposto de renda pessoa física, pois com a era digital, facilitou o cruzamento das informações, sendo confirmada pela correlação positiva de $(0,812)$, consolidando-se, em 2011, quando a Receita Federal, tornou obrigatória à entrega das declarações de imposto de renda, em formato digital para todos os contribuintes, sendo confirmada pela correlação positiva $(0,624)$ entre a DMED e a Declaração Digital.

\section{CONCLUSÃO}

A Evasão Fiscal do Imposto Sobre a Renda da Pessoa Física, sempre foi um grande desafio para Receita Federal, tanto que foram criadas algumas leis que demonstraram que a evasão fiscal se constituía em crime, além de medidas como criação de obrigações acessórias para tentar combatê-la.

Uma das medidas mais importantes da Receita Federal foi a era digital, quando as declarações começaram a ser entregues via internet, embora tenha se iniciado em 1997, a obrigatoriedade para todos os contribuintes enviarem suas declarações por meio eletrônico, se deu somente em 2011, nesse período houve o aumento da entrega declaração de imposto de imposto de renda pessoa física, dados demonstrado na tabela 2, onde é apresentada uma correlação positiva $(0,763)$ que a entrega da declaração de imposto de renda pessoa física, aumenta quando a exigência da entrega da declaração de imposto de renda passa a ser da forma digital.

A Receita Federal também criou outras Obrigações Acessórias, a que teve maior impacto no período abordado nesse trabalho, de 2002 a 2012, foi a criação da DMED, o que possibilitou o cruzamento de algumas informações, ajudando assim a Receita Federal a aumentar a sua arrecadação e diminuindo a Evasão Fiscal, demonstrada na analise de dados na tabela 3 onde a correlação positiva $(0,624)$, apresenta claramente que a partir de 2009 quando a DMED foi criada houve amento da arrecadação, intensificado muito mais, quando em 2011 as declarações em papel já não era mais aceita.

Pode-se verificar que o trabalho da Receita Federal no combate a Evasão Fiscal do Imposto Sobre a Renda da Pessoa Física, não terá fim, mesmo porque o contribuinte para pagar menos imposto, tenta se utilizar de algumas lacunas nas leis para se beneficiar, o presente trabalho tratou de um período, em que a internet foi de grande ajuda para Receita Federal diminuir os índices da Evasão Fiscal, agora com a internet sendo indispensável a todos, o que 
Zittei, M. V. M., Santos, C. A., Lugoboni, L. F.; O Combate à Evasão Fiscal do Imposto sobre a Renda da Pessoa Física.

pode ser acompanhado é a grande evolução da própria Receita Federal em criar algumas artimanhas para estar à frente do contribuinte que queira transgredir as leis e verificar quais as mais recentes medidas que a Receita Federal tem tomado para diminuir a Evasão Fiscal do Imposto Sobre a Renda da Pessoa Física.

O presente trabalho, também sugere a analise de outros impostos e o impacto das obrigações acessórias em relação à evasão fiscal e o próprio controle dos órgãos responsáveis. Hoje se fala muito em SPED Contribuições e SPED Contábil, seria interessante verificar o impacto dessas duas obrigações acessórias em relação ao controle da Receita Federal e se influenciaram no combate a Evasão Fiscal.

\section{REFERÊNCIAS}

ACIB, Associação Comercial e Industrial de Bauru. Declarações de Imposto de Renda Pessoa Física Entregues a Receita Federal em 2011. Disponível em:

$<$ http://www.acib.org.br/site/conteudo/923-receita-federal-recebeu-24-milhoes-dedeclarac.html>. Acesso em: 13 abr. 2013.

AGÊNCIA BRASIL. Declarações de Imposto de Renda Pessoa Física Entregues a Receita Federal em 2010.

Disponível em: <http://aquiacontece.com.br/noticia/2010/05/01/receita-recebeu24678740-declaracoes-do-imposto-de-renda-2010-pela-internet>. Acesso em: 13 abr. 2013.

ANDRADE, Maria Margarida de. Como preparar Trabalhos para Cursos de PósGraduação. 4. Ed. São Paulo: Atlas, 2001.

BRASIL. Constituição da Republica Federativa do Brasil, de 05/10/1988. Diário Oficial - Republica Federativa do Brasil: Poder Legislativo. Brasília, DF, 1988. . Emenda Constitucional $n^{\circ} 33$ de 11 de dezembro de 2001. Altera os artigos 149,155 e 177 da Constituição Federal. Diário Oficial - Republica Federativa do Brasil: Poder Legislativo. Brasília, DF, 2001.

Emenda Constitucional $n^{\circ} 42$ de 19 de dezembro de 2003. Altera o Sistema Tributário Nacional e dá outras providências. Diário Oficial - Republica Federativa do Brasil: Poder Executivo. Brasília, DF, 2003. 
Zittei, M. V. M., Santos, C. A., Lugoboni, L. F.; O Combate à Evasão Fiscal do Imposto sobre a Renda da Pessoa Física.

. Lei $\mathrm{n}^{\mathrm{o}} 4.320$ de 17 de março de 1964 . Dispõe sobre normas gerais de direito financeiro para elaboração e controle de orçamentos e balanços da União, dos Estados, Municípios e do Distrito Federal. Diário Oficial da União, Brasília, 17.03.1964.

. Lei $\mathrm{n}^{\circ} 5.172$ de 25 de outubro de 1966. Dispõe sobre o código tributário nacional. Diário Oficial da União, Brasília, 1966.

Lei $n^{\circ} 7.713$ de 22 de dezembro de 1988. Altera a legislação do imposto de renda e dá outras providências. Diário Oficial da União, Brasília, 1988.

Lei 8.137 de 27 de dezembro de 1990. Define crimes contra a ordem tributária, econômica e contra as relações de consumo, e dá outras providências. Diário Oficial da União. Brasília, Distrito Federal. pub. 28 de dez. de 1990.

. Lei ${ }^{\circ} 9.250$ de 26 de dezembro de 1995. Altera a Legislação do Imposto de

Renda das Pessoas Físicas e dá outras Providências. Diário Oficial da União, Brasília, 27.12.1995.

. Arrecadação da Receita Federal Imposto Renda Pessoa Física. Disponível em: <http://www.receita.fazenda.gov.br/Historico/Arrecadacao/ResultadoArrec/default.htm>. Acesso em: 06 abr. 2013. . O que é IR?

Disponível em: <http://www.brasil.gov.br/sobre/economia/imposto-de-renda/o-que-eo-ir/print>. Acesso em: 10 mar. 2013.

CARvalho, Paulo Barros de. Curso de Direito Tributário. Três ed. São Paulo; Editora Saraiva. 1988.

DIÁRIO DE CUIABÁ. Declarações de Imposto de Renda Pessoa Física Entregues a Receita Federal em 2005.

Disponível em: <http://www.diariodecuiaba.com.br/detalhe.php?cod=217135>. Acesso em: 12 abr. 2013.

DOURADOS NEWS. Declarações Entregues a Receita Federal em 2002. Disponível em: <http://www.douradosnews.com.br/arquivo/recorde-receita-recebe-15-5-milhoes-dedeclaracoes-652b90fd1e9527f548f488e046c7914e>. Acesso em: 12 abr. 2013. 
Zittei, M. V. M., Santos, C. A., Lugoboni, L. F.; O Combate à Evasão Fiscal do Imposto sobre a Renda da Pessoa Física.

FABRETTI, Láudio Camargo; FABRETTI, Dilene Ramos. Direito Tributário Para os Cursos de Administração e Ciências Contábeis. Seis ed. São Paulo; Editora Atlas. 2007

FOLHA DE SÃO PAULO. Declarações de Imposto de Renda Pessoa Física Entregues a Receita Federal em 2003.

Disponível em: <http://www1.folha.uol.com.br/fsp/dinheiro/fi0105200308.htm>. Acesso em: 12 abr. 2013.

Declarações de Imposto de Renda Pessoa Física Entregues a Receita Federal em 2004.

Disponível em: <http://www1.folha.uol.com.br/fsp/dinheiro/fi0105200423.htm> Acesso em: 12 abr. 2013.

FOUCAULT, Michel. A verdade e as formas jurídicas. Rio de Janeiro: Nau, 1996.

G1 ECONOMIA. Declarações de Imposto de Renda Pessoa Física Entregues a Receita Federal em 2012. Disponível em:

<http://g1.globo.com/economia/imposto-de-renda/2012/noticia/2012/05/receitarecebeu-25-milhoes-de-declaracoes-de-ir.html>. Acesso em: 13 abr. 2013.

GIL, Antonio Carlos. Como elaborar projetos de pesquisa. São Paulo: Atlas, 1996.

GUIMARÃES, Ylves José de Miranda. O Tributo - análise ontológica à luz do direito natural e do direito positivo. São Paulo; Editor Max Limonad Ltda.; 1983.

HARADA, Kiyoshi. Direito Financeiro e Tributário. São Paulo; Atlas, 1995.

HUCK, Hermes Marcelo. Evasão e elisão - rotas nacionais e internacionais do planejamento tributário. São Paulo: Saraiva, 1997.

HUGON, Paul. O Imposto - teoria moderna e principais sistemas. São Paulo; Editora Renascença S.A., 1945.

JANTSCH E KANOMATA ADVOGADOS. DMED. Disponível em:

$<$ http://jkadvogados.wordpress.com/2010/05/20/entenda-a-dmed-declaracao-deservicos-medicos/>. Acesso em: 06 abr. 2013. 
Zittei, M. V. M., Santos, C. A., Lugoboni, L. F.; O Combate à Evasão Fiscal do Imposto sobre a Renda da Pessoa Física.

LUÍS OSVALDO GROSSMANN. Declarações de Imposto de Renda Pessoa Física Entregues a Receita Federal em 2009. Disponível em:

<http://convergenciadigital.uol.com.br/cgi/cgilua.exe/sys/start.htm?infoid=18670\&sid =11\#.UYV_iaKG2s8>. Acesso em: 13 abr. 2013.

MACHADO, Hugo de Brito. Curso de direito tributário. 21. Ed. São Paulo: Malheiros, 2002.

MARINS, James. Elisão tributária e sua regulação. São Paulo: Dialética, 2002.

MINISTÉRIO DA FAZENDA - GOVERNO FEDERAL BRASIL. Crescimento Econômico Brasileiro. Período de 2002 a 2011. Disponível em:

$<$ http://www.fazenda.gov.br/portugues/docs/perspectiva-economiabrasileira/edicoes/Economia-Brasileira-Em-Perpectiva-Mar-Abr12-alterado.pdf $>$. Acesso em: 13 abr. 2013.

Crescimento Econômico Brasileiro. Período de 2012. Disponível em:

<http://www.fazenda.gov.br/portugues/docs/perspectiva-economiabrasileira/edicoes/Economia\%20Brasileira\%20Perspectiva--PT--17ed.pdf>. Acesso em: 13 abr. 2013.

O JORNAL ON LINE. Declarações de Imposto de Renda Pessoa Física Entregues a Receita Federal em 2007.

Disponível em: <http://www.ojornalonline.com.br/home/conteudo.asp?codigo=1888>. Acesso em: 12 abr. 2013.

PAULSEN, Leandro. Direito tributário - constituição e código tributário à luz da doutrina e jurisprudência. 7. ed. Porto Alegre: Livraria do Advogado, 2005.

PEIXOTO. Marcelo Magalhães. Planejamento tributário. In: PEIXOTO. Marcelo Magalhães. (Coord.). São Paulo: Quartier Latim, 2004. 
Zittei, M. V. M., Santos, C. A., Lugoboni, L. F.; O Combate à Evasão Fiscal do Imposto sobre a Renda da Pessoa Física.

PEREIRA, César A. Guimarães. Elisão tributária e função administrativa. São Paulo: Dialética, 2001.

QUEIROZ, Luís Cesar Souza de. Imposto Sobre a Renda. Rio de Janeiro: Forense, 2003.

SABAGG, Eduardo. Manual de Direito Tributário. 3 Ed., São Paulo, Saraiva, 2011.

SANTOS, André Luiz da Silva dos. A estrutura lógico-formal do imposto sobre a renda e proventos de qualquer natureza. A regra-matriz de incidência. Jus Navigandi, Teresina, ano16, n.3030, 18 out. 2011.Disponível em: 〈http://jus.com.br/revista/texto/20233〉. Acesso em 17/03/2013.

SECRETARIA DA RECEITA FEDERAL. Constituição Federal - Título VI- Da Tributação e Do Orçamento.

Disponível em:

<http://www.receita.fazenda.gov.br/Legislacao/ConstituicaoFederal/ConstFedTituloVI .htm>. Acesso em: 16 mar. 2013.

1982 A 1990 (a): O Lançamento por Homologação de Bases Correntes.

Disponível

em:http://www.receita.fazenda.gov.br/Memoria/irpf/historia/hist1982a1990.asp - acesso em 18/03/2013.

1991 A 1996 (b): Instituição da declaração de ajuste anual por meio eletrônico. Disponível em:

http://www.receita.fazenda.gov.br/Memoria/irpf/historia/hist1991a1996.asp - acesso em 18/03/2013.

1997 A 2006 (c): O Avanço tecnológico: segurança, rapidez e facilidade no preenchimento e na entrega da declaração.

Disponível em:

http://www.receita.fazenda.gov.br/Memoria/irpf/historia/hist1997a2006.asp acesso em 18/03/2013. 
Zittei, M. V. M., Santos, C. A., Lugoboni, L. F.; O Combate à Evasão Fiscal do Imposto sobre a Renda da Pessoa Física. 2007 A 2009 (d): A Receita Federal do Brasil Disponível em:

http://www.receita.fazenda.gov.br/Memoria/irpf/historia/hist2007a2009.asp - acesso em $18 / 03 / 2013$

_ 2011 (e): Perguntão Declaração de Imposto de Renda Pessoa Física 2011. Disponível em:

http://www.receita.fazenda.gov.br/PessoaFisica/IRPF/2011/perguntao/assuntos/aprese ntacao-e-locais-de-entrega.htm - acesso em 28/04/2013.

SIENOREG-PR, Sindicato dos Escrivães, Notários e Registradores do Paraná. DOI. Disponível em:

<http://www.sienoregpr.org.br/noticia20110509b.html>. Acesso em: 06 abr. 2013.

UNAFISCO SINDICAL, Sindicato Nacional dos Auditores-Fiscais da Receita Federal do Brasil. Declarações de Imposto de Renda Pessoa Física Entregues a Receita Federal em 2008. Disponível em:

<http://www2.unafisco.org.br/publicar/principal/texto_noticias.php?ID=8525>. Acesso em: 12 abr. 2013.

UOL ECONOMIA. Declarações de Imposto de Renda Pessoa Física Entregues a Receita Federal em 2006. Disponível em:

$<$ http://economia.uol.com.br/imposto-de-renda/noticias/redacao/2006/04/28/ir-2006receita-alcanccedila-a-expectativa-e-recebe-22-milhotildees-de-declaraccedilotildees.htm>. Acesso em: 12 abr. 2013.

. Declarações que caíram na malha fina em 2012. Disponível em: <http://economia.uol.com.br/noticias/redacao/2012/12/10/receita-libera-consulta-ao-ultimolote-do-ir-mais-de-600-mil-caem-na-malha-fina.htm>. Acesso em: 10 mar. 2013.

VILLENA, Gabriel. DIMOB. Disponível em:

<http://www.bonnaconsultores.com.br/noticias.php?id=359> . Acesso em: 06 abr. 2013. 